\title{
ẢNH HƯỞNG CỦA THAN SINH HỌC \\ THAY THẾ MỘT PHẦN PHÂN KHOÁNG ĐẾN SINH TRƯởNG VÀ NĂNG SUÂT NGÔ \\ TRỒNG TẠI THÀNH PHỐ VIẸTT TRÌ - TỈNH PHÚ THỌ
}

Efects of biochar alternatives to partial of fertilizer to growth, yield of maize in Viet Tri - Phu Tho

\author{
ThS. Hoàng Thị Lệ Thu* , ThS. Trần Thành Vinh" \\ ThS. Nguyễn Quang Trung*", ThS. Phạm Thị Mai Trang***
}

TÓM TẮT

Nghiên cứu nhằm đánh giá ảnh hương của việc sủ dụng than sinh hoc thay thế một phần phân khoáng đến sinh trương và năng suất ngô tại Việt Trì, Phú Thọ. Thí nghiệm thực hiện trên giống ngô VS36. Các công thức thí nghiệm được bố trí theo kiểu khối ngẫu nhiên hoàn chỉnh với 3 lần nhắc lại. Theo dõi các chỉ tiêu về sinh truởng, năng suất và đánh giá hiệu quả sản xuất ngô. Kết quả thí nghiệm chỉ ra rằng khi sủ dụng than sinh hoc thay thế cho $20 \%$ luợng phân khoáng, cây ngô vẫn có khả năng sinh trương phát triển tốt và cho năng suất đạt 42,68 tạ/ha tương đương với công thức đối chứng.

Tù khóa: Than sinh học, cây ngô, sinh trưong, năng suất.

\section{ABSTRACT}

Experimental study to evaluate the effect of biochar alternatives to partial fertilizer on the growth and yield of maize in Vietnam Tri, Phu Tho. The experiment was carried out on cultivar VS36. The experiment consists of 4 treatments, was replicated three times in a complete randomized block design. Subscribe to the growth targets, corn yields. Results showed that use of biochar as a substitute for $20 \%$ of mineral fertilizers, the corn still good growth and development and high yield.

Key word: biochar, maize, growth, yield.

\section{1. Đặt vấn đề}

Theo kết quả khảo sát của Cục Trồng trọt - Bộ Nông nghiệp và Phát triển nông thôn cho biết, hiệu suất sử dụng phân bón ở Việt Nam hiện nay mới chỉ đạt 40 - 45\% đối với đạm, lân từ $40-45 \%$ và kali từ $40-50 \%$. Do đó phần lớn phân nằm lại trong đất, bị rửa trôi theo nước, hoặc bị bốc hơi gây ô nhiễm nguồn nước và không khí.

Trước vấn đề đó, than sinh học (black carbon hay biochar) đang được nhiều nhà khoa học trên thế giới quan tâm và ví như là "vàng đen” cho ngành nông nghiệp.

Biochar là sản phẩm của quá trình nhiệt phân chất hữu cơ ở nhiệt độ cao trong điều kiện yếm khí (Lehmann et al.,2006). Bổ sung biochar vào đất có thể làm thay đổi đặc tính lý hóa đất, tăng lượng dinh dưỡng trong đất và tăng khả năng phát triển nấm cộng sinh rễ cây (Ishii and Kadoya, 1994), là nơi trú ngụ, bảo vệ cho nấm và vi sinh vật trong đất (Warnock et al., 2007). Việc sử dụng biochar để bón vào đất canh tác đã và đang ngày càng được chú ý đến như

\footnotetext{
* Trường Đại học Hùng Vương
}

** Trường Đại học Tân Trào 
là một cách để làm tăng nguồn chứa cacbon, giảm hiệu ứng nóng lên toàn cầu, cải thiện khả năng giữ nước, dinh dưỡng trong đất cũng như kiểm soát sự di động của nhiều chất gây ô nhiễm môi trường (Lehmann et al., 2006; Verheijen et al., 2009; Van Zwieten et al., 2010). Hơn nữa, việc bón biochar vào đất còn làm tăng hiệu quả sử dụng nước, tăng độ phì của đất và sản lượng cây trồng do làm giảm sự rửa trôi các chất dinh dưỡng và thậm chí cung cấp các chất dinh dưỡng cho cây (Glaser et al., 2002; Lehmann et al., 2003).

Việc sử dụng than sinh học ở nước ta cho cây trồng chỉ mới bắt đầu được quan tâm nghiên cứu trong thời gian gần đây. Trong khi đó, đất trồng trọt ở tỉnh Phú Thọ đa phần là đất đồi núi dốc, khả năng giữ nước kém, đất dễ bị rửa trôi.

Đó là lý do để chúng tôi thực hiện nghiên cứu này.

\section{Vật liệu và phương pháp nghiên cứu}

+ Thời gian và địa điểm: Thí nghiệm được thực hiện trong vụ đông xuân 2014 - 2015 tại xã Chu Hóa - Việt Trì - Phú Thọ.

+ Vật liệu nghiên cứu: Giống ngô VS36 do Viện nghiên cứu ngô chọn tạo; Than sinh học được chế biến từ rơm rạ bằng phương pháp đốt gián tiếp.

\section{+ Phuơng pháp bố trí thí nghiệm}

- Các công thức thí nghiệm

Công thức 1: Bón phân 100\% theo quy trình (Nền)

Công thức 2: $80 \%$ Nền +10 tấn than sinh học/ha

Công thức 3: $60 \%$ Nền +10 tấn than sinh học/ha

Công thức 4: 40\% Nền + 10 tấn than sinh học/ha

Trong đó: Lượng phân bón cho 1 ha theo quy trình là $180 \mathrm{~N}+90 \mathrm{P}_{2} \mathrm{O}_{5}+120 \mathrm{~K}_{2} \mathrm{O}$

Cách bón như sau:

Bón lót: bón toàn bộ phân lân + than sinh học

Bón thúc lần 1: Khi ngô được 3 - 4 lá, bón 1/3 lượng $\mathrm{N}+1 / 3$ lượng kali. Kết hợp vun nhẹ để lấp phân.

Bón thúc lần 2: Khi ngô được 7 - 9 lá, bón bón 1/3 lượng $\mathrm{N}+1 / 3$ lượng kali. Vun lấp phân và vun cao luống

Bón thúc lần 3: Khi ngô xoắn nõn, bón hết lượng phân đạm và phân kali còn lại kết hợp vun cao lần cuối.

Thí nghiệm được bố trí theo kiểu khối ngẫu nhiên hoàn chỉnh $(\mathrm{RCB})$, với 3 lần nhắc. Diện tích ô thí nghiệm: $10 \mathrm{~m}^{2}$.

+ Các chỉ tiêu theo dõi: Theo dõi các chỉ tiêu về sinh trưởng; năng suất và các chỉ tiêu liên quan đến hiệu quả kinh tế.

+ Xủ̉ lý số liệu: Các số liệu thu được xử lý theo chương trình Excel và IRRISTAT.

\section{Kết quả và thảo luận}

3.1. Anh hương của việc sử dụng than sinh học thay thế một phần phân khoáng đến động thái tăng truởng chiều cao của giống ngô VS36 


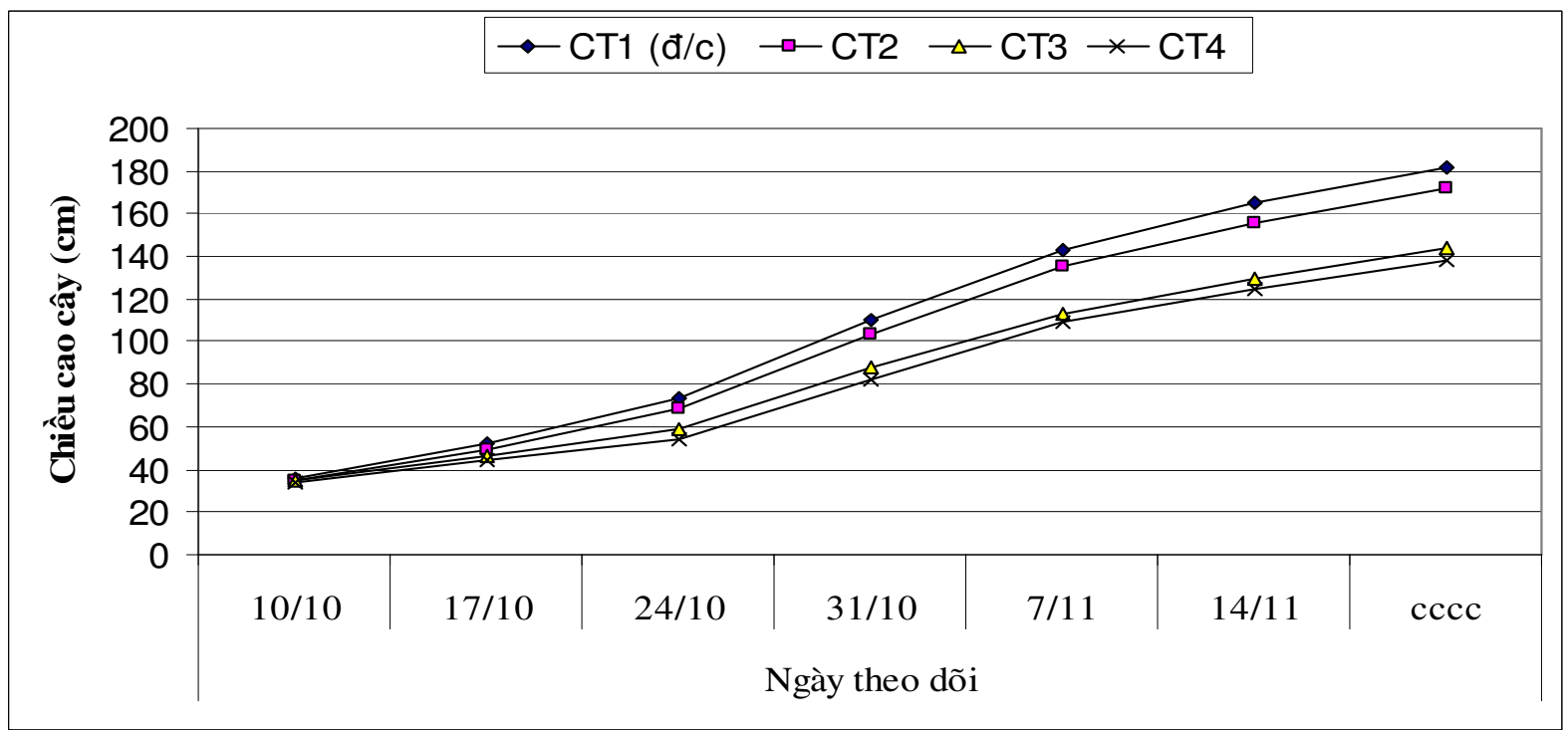

Hình 1: Động thái tăng trương chiều cao

Qua hình 1 cho thấy các công thức khi sử dụng than sinh học thay thế cho phân khoáng ở các mức độ khác nhau đều có mức tăng trưởng chiều cao cây khác nhau. Sử dụng 10 tấn phân chuồng thay thế cho $20 \%$ lượng phân khoáng, cây ngô có tốc độ tăng trưởng tương đương với công thức đối chứng. Đối với cây ngô, chiều cao cây là đặc tính di truyền phụ thuộc vào giống và chiều cao cây lớn không phải là yếu tố có lợi vì nếu cây quá cao sẽ ảnh hưởng đến quá trình thụ phấn thụ tinh và khả năng chống đổ của cây. Tuy nhiên, khi giảm lượng phân khoáng từ trên $20 \%$ mặc dù đã thay thế bằng than sinh học thì mức độ tăng trưởng về chiều cao cây lại thấp hơn nhiều so với đối chứng. Điều đó chứng tỏ vai trò cung cấp chất dinh dưỡng của than sinh học còn hạn chế.

\subsection{Anh hưởng của việc sử dụng than sinh học thay thế một phần phân khoáng đến} động thái tăng trưởng số lá của giống ngô VS36

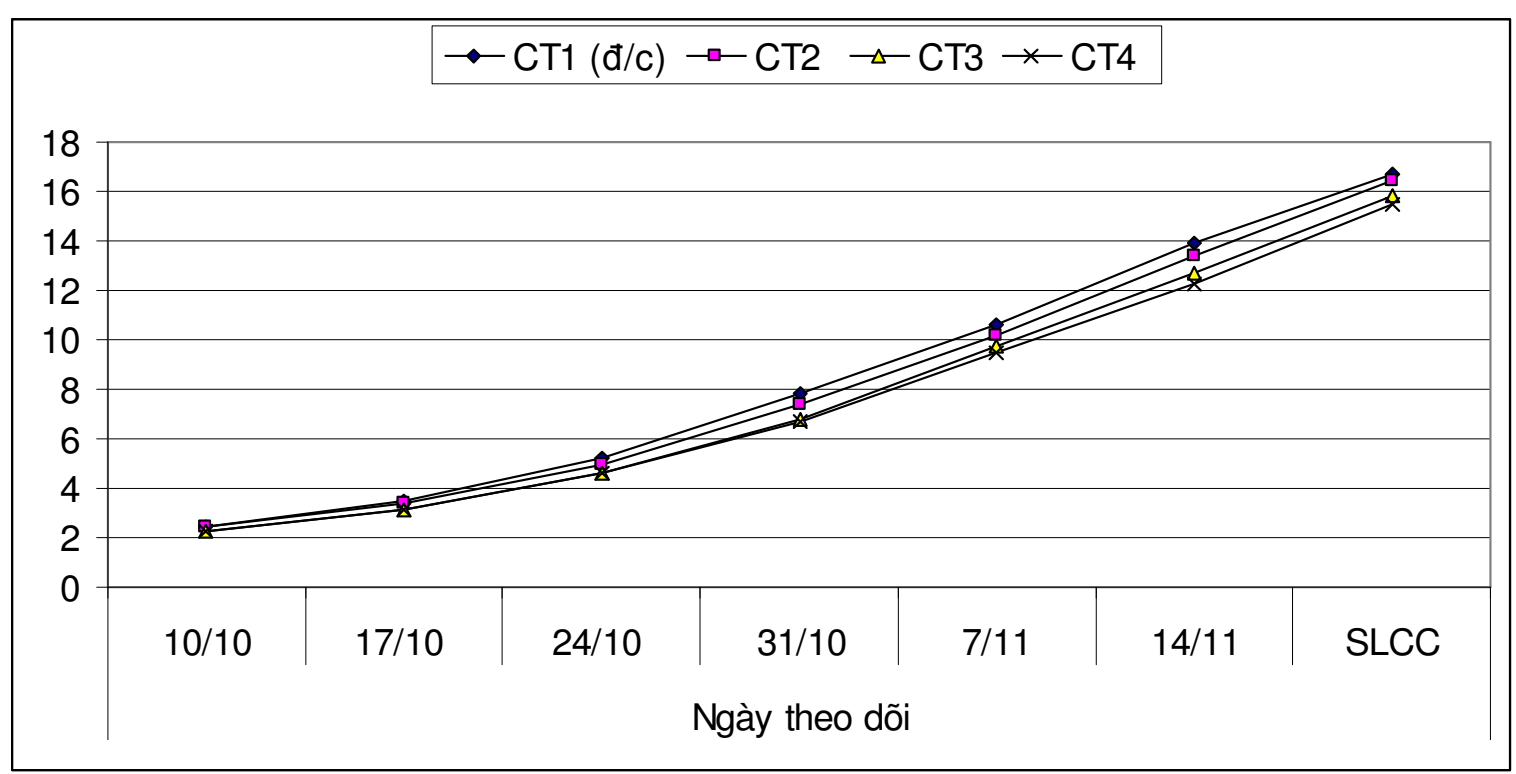

Hình 2: Động thái ra lá

Đánh giá ảnh hưởng của việc thay thế một phần phân khoáng bằng than sinh học đến động thái ra lá của giống ngô VS36 được thể hiện trong hình 2. Kết quả cho thấy: chưa có sự khác biệt rõ ràng ở lần đo ngày 10/10, số lá dao động từ 2,3 - 2,4 lá/cây. Thời điểm từ 17/10 đến 14/11: Trong 
giai đoạn này bộ rễ bắt đầu phát triển hoàn chỉnh bao gồm: Rễ chính, rễ phụ và rễ chân kiềng phát triển đầy đủ, ăn sâu và rộng hơn nên khả năng hút dinh dưỡng mạnh hơn. Đồng thời, do đặc tính của than sinh học có khả năng hấp thụ nước tốt và tăng cường khả năng hút chất dinh dưỡng của cây nên công thức 2 mặc dù lượng phân khoáng bón cho cây đã giảm đi $20 \%$ nhưng tốc độ ra lá vẫn tương đương với công thức đối chứng. Công thức 3 và công thức 4 , mặc dù đã được thay thế bằng than sinh học nhưng lượng phân khoáng đã bị giảm đi khá nhiều nên tốc độ ra lá chậm hơn. Do đó, số lá cuối cùng giữa các công thức nghiên cứu có sự khác nhau. Công thức đối chứng có số lá đạt cao nhất là 16,7 lá; công thức 2 có số lá tương đương với công thức 1 . Công thức 3 và công thức 4 có số lá thấp hơn đối chứng xấp xỉ từ 1 - 1,2 lá.

3.3. Anh hưởng của việc sử dụng than sinh học thay thế một phần phân khoáng đến chiều cao thân, chiều cao đóng bắp và đường kính thân của giống ngô VS36

Kết quả nghiên cứu về ảnh hưởng của việc sử dụng than sinh học thay thế một phần phân khoáng đến chiều cao thân, chiều cao đóng bắp và đường kính thân của giống ngô VS36 được trình bày trong bảng 1 .

\begin{tabular}{|c|c|c|c|c|}
\hline \multirow{2}{*}{ Công thức } & \multirow{2}{*}{ Chiều cao thân $(\mathrm{cm})$} & \multicolumn{2}{|c|}{ Chiều cao đóng bắp } & \multirow{2}{*}{ ĐK thân $(\mathrm{cm})$} \\
\cline { 3 - 4 } & & $(\mathrm{cm})$ & $T y$ lê $C 円 B(\%)$ & \\
\hline CT1 & 132,7 & 56,6 & 0,43 & 1,74 \\
\hline CT2 & 127,3 & 51,2 & 0,40 & 1,67 \\
\hline CT3 & 120,6 & 42,5 & 0,35 & 1,43 \\
\hline CT4 & 114,4 & 40,2 & 0,35 & 1,34 \\
\hline$P_{r}$ & $<0,05$ & $<0,05$ & & $<0,05$ \\
\hline$L S D_{0,5}$ & 9,10 & 3,9 & & 0,1 \\
\hline$C V \%$ & 3,7 & 4,1 & & 3,3 \\
\hline
\end{tabular}

Bảng 1. Anh hưởng của lựng bón tan sinh học đến chiều cao thân, chiều cao đóng bắp và đường kính thân của giống ngô VS36

* Chiều cao thân: Qua kết quả thí nghiệm cho thấy chiều cao thân giữa các công thức có sự sai khác chắc chắn ở độ tin cậy $95 \%$. Trong đó $\mathrm{CT} 1$ và $\mathrm{CT} 2$ có chiều cao thân thấp tương đương nhau. Mặc dù đã được thay thế bằng than sinh học nhưng nếu giảm quá nhiều lượng phân khoáng so với quy trình (giảm trên $20 \%$ lượng phân khoáng so với quy trình) thì làm cho khả năng sinh trưởng của cây ngô giảm đi rõ rệt. Điều đó cho thấy vai trò cung cấp chất dinh dưỡng cho cây từ than sinh học là chưa rõ rệt. Ở đây than sinh học chỉ có vai trò là chất tăng cường khả năng hấp thu dinh dưỡng, tăng khả năng giữ nước và giữ chất dinh dưỡng.

* Chiều cao đóng bắp và tỷ lệ chiều cao đóng bắp: Chiều cao đóng bắp được tính từ gốc đến đốt mang bắp hữu hiệu đầu tiên. Chiều cao đóng bắp hợp lý giúp cây ngô dễ nhận phấn, tăng chống đổ và có ý nghĩa rất quan trọng trong việc áp dụng các biện pháp cơ giới hóa. Qua dữ liệu bảng 1 cho thấy, CT1 có chiều cao đóng bắp cao nhất là 56,6,6cm tương ứng với tỷ lệ chiều cao trên thân là 43,0\%. Các công thức cùng bón 10 tấn than sinh học/ha nhưng lượng phân khoáng càng giảm thì đều có chiều cao đóng bắp thấp hơn tương ứng với tỷ lệ chiều cao trên thân từ $35-40 \%$. Như vậy kết quả nghiên cứu trên cũng phù hợp với nhận định của Nguyễn Thế Hùng (1996), trong điều kiện nhiệt độ cao, dinh dưỡng đầy đủ, cây sinh trưởng tốt, bắp thường đóng cao hơn bình thường. 
* Đường kính thân: Đường kính thân là một chỉ tiêu quan trọng liên quan đến khả năng sinh trưởng và tính chống đổ của cây ngô. Đường kính thân cây được đo cách gốc $10 \mathrm{~cm}$. Kết quả nghiên cứu cho thấy đường kính thân cây ngổ ở các công thức có sự sai khác một cách rõ rệt ở độ tin cậy 95\%. Trong đó CT1 và CT2 có đường kính thân tương đương nhau dao động từ $1,67-1,74 c m$. Cùng bón 10 tấn than sinh học/ha nhưng giảm đi từ 40 - 60\% lượng phân khoáng đường kính thân cây giảm đi rõ rệt dao động từ $1,34-1,43 \mathrm{~cm}$.

3.4. Anh hưởng của việc sử dụng than sinh học thay thế một phần phân khoáng đến các yếu tố cấu thành năng suất của giống ngô VS36.

Qua bảng 2 cho thấy:

* Số bắp hữu hiệu/cây: Là chỉ tiêu quan trọng ảnh hưởng đến năng suất ngô, nó phụ thuộc chủ yếu vào tính di truyền của giống, ngoài ra còn phụ thuộc vào kỹ thuật chăm sóc. Qua sản xuất trên thực tế cũng như các công thức thí nghiệm để dinh dưỡng tập trung nuôi bắp số 1 nên bắp hữu hiệu giữa các công thức là 1 bắp/cây.

* Chiều dài đuôi chuột $(\mathbf{c m})$ : Kết quả đánh giá cho thấy công thức 1 có chiều dài đuôi chuột ngắn nhất là $1,56 \mathrm{~cm}$. Công thức 2 , khi giảm đi $20 \%$ lượng phân khoáng và thay thế bằng 10 tấn than sinh học thì chiều dài đuôi chuột cũng không có sự sai khác với đối chứng. Các công thức còn lại, bắp ngô đều có chiều dài đuôi chuột lớn hơn so với đối chứng. Điều đó cho thấy việc bổ sung than sinh học đã có tác dụng tăng cường khả năng hấp thu nước và dinh dưỡng, giảm sự mất chất dinh dưỡng nên mặc dù đã giảm đi $20 \%$ lượng phân khoáng nhưng không ảnh hưởng đến sinh trưởng của cây ngô.

* Chiều dài bắp và đường kính bắp $(\mathbf{c m})$ : Phụ thuộc vào đặc tính di truyền của từng giống, điều kiện ngoại cảnh, kỹ thuật chăm sóc và chế độ dinh dưỡng. Cây ngô muốn có năng suất cao thì sức chứa các chất dự trữ phải lớn tức là bắp ngô phải dài và có đường kính bắp lớn thì mới chứa được số lượng hạt nhiều. Các công thức có chiều dài bắp dao động từ $14,80-17,42 \mathrm{~cm}$, đường kính bắp từ $2,75-3,74 \mathrm{~cm}$ trong đó các công thức có lượng phân khoáng giảm đi từ $20 \%$ bắp ngô đều có chiều dài và đường kính bắp nhỏ hơn so với đối chứng một cách chắc chắn ở độ tin cậy $95 \%$.

\begin{tabular}{|c|c|c|c|c|c|c|c|}
\hline \multirow[b]{2}{*}{ Công thức } & \multicolumn{7}{|c|}{ Chì tiêu } \\
\hline & $\begin{array}{c}\text { Số bắp } \\
\text { hữu } \\
\text { hiệu/cây }\end{array}$ & $\begin{array}{l}\text { Chiều dài } \\
\text { đuôii } \\
\text { chuột } \\
\text { (cm) }\end{array}$ & $\begin{array}{l}\text { Chiều dài } \\
\text { bắp }(\mathbf{c m})\end{array}$ & $\begin{array}{l}\text { Đường } \\
\text { kính bắp } \\
\text { (cm) }\end{array}$ & $\begin{array}{c}\text { Số } \\
\text { hàng/bắp } \\
\text { (hàng) }\end{array}$ & $\begin{array}{c}\text { Số } \\
\text { hạt/hàng } \\
\text { (hạt) }\end{array}$ & $\begin{array}{l}\text { P } 1000 \\
\text { hạt (g) }\end{array}$ \\
\hline CT1 (d/c) & 1,0 & 1,56 & 17,42 & 3,74 & 14,81 & 32,16 & 213,54 \\
\hline CT2 & 1,0 & 1,62 & 16,84 & 3,54 & 14,26 & 30,68 & 208,70 \\
\hline CT3 & 1,0 & 1,71 & 15,42 & 2,86 & 13,74 & 27,84 & 198,62 \\
\hline CT4 & 1,0 & 2,16 & 14,80 & 2,75 & 13,68 & 25,62 & 197,36 \\
\hline$L S D_{(0,05)}$ & & 0,19 & 1,75 & 0,30 & 1,55 & 2,75 & 22,87 \\
\hline$C V \%$ & & 5,3 & 5,4 & 4,7 & 5,5 & 4,7 & 5,6 \\
\hline
\end{tabular}

Bảng 2: Ảnh hưởng của việc sủ dụng than sinh học thay thế một phần phân khoáng đến các yếu tố cấu thành năng suất của giống ngô VS36 
* Số hàng/bắp và số hạt/hàng: Số hàng/bắp và số hạt/hàng của các công thức theo dõi dao động từ 13,68 - 14,81 hàng/bắp và 25,62 - 32,16 hạt/hàng. Kết quả này cho thấy giảm đi quá nhiều lượng phân khoáng mặc dù đã được thay thế bằng than sinh học thì yếu tố liên quan đến năng suất như số hạt/hàng đã bị giảm đi rõ rệt.

* Trọng lượng 1.000 hạt $(\mathrm{g})$ : Phụ thuộc chủ yếu vào đặc điểm di truyền của từng dòng. Ngoài ra còn phụ thuộc nhiều vào điều kiện thời tiết, đất đai, kỹ thuật canh tác, chế độ dinh dưỡng và nước tưới. Nếu sau khi ngô trỗ cờ - thụ phấn - phun râu mà gặp điều kiện không thuận lợi như thiếu nước, sâu bệnh hại... làm hạn chế quá trình vận chuyển dinh dưỡng về hạt, hạn chế sự tích luỹ vật chất khô và giảm khối lượng hạt. Qua bảng 3 cho thấy: Trọng lượng 1.000 hạt ở các công thức không có sự sai khác nhau một cách rõ rệt.

\subsection{Anh hương của việc sử dụng than sinh học thay thế một phần phân khoáng đến} năng suất của giống ngô VS36

Qua kết quả bảng 3 cho thấy:

Năng suất lý thuyết (NSLT): Trên giống ngô VS36, thay thế cùng một lượng than sinh học ở các mức giảm lượng phân khoáng khác nhau thì năng suất ngô khác nhau. Công thức đối chứng cho năng suất lý thuyết đạt cao nhất là 57,97 tạ/ha. Các công thức còn lại đều cho năng suất lý thuyết thấp hơn so với đối chứng dao động từ 39,34 - 52,04 tạ/ha.

Năng suất thực thu (NSTT): Năng suất thực thu là chỉ tiêu tổng hợp các yếu tố để đánh giá về giống, các biện pháp kỹ thuật, chế độ dinh dưỡng và là mục tiêu cuối cùng trong sản xuất ngô. Qua kết quả thí nghiệm ở vụ Đông 2014 cho thấy: Năng suất thực thu ở các công thức dao động từ 29,05 - 45,22 tạ/ha. Trong đó công thức 1 và công thức 2 có năng suất như nhau ở độ tin cậy $95 \%$. Công thức 3 và công thức 4 đều có năng suất thực thu thấp hơn so với đối chứng một cách chắc chắn. Như vậy, khi giảm $20 \%$ lượng phân khoáng bón cho cây ngô và thay thế bằng 10 tấn than sinh học không ảnh hưởng đến sinh trưởng và năng suất của cây ngô.

\begin{tabular}{|c|c|c|}
\hline Công thức & $\begin{array}{l}\text { Năng suất lý thuyết } \\
(t a ̣ / h a)\end{array}$ & $\begin{array}{c}\text { Năng suất thục thu } \\
(t a ̣ / h a)\end{array}$ \\
\hline$C T 1(d / c)$ & 57,97 & 45.22 \\
\hline$C T 2$ & 52,04 & 42,68 \\
\hline CT3 & 43,31 & 33,72 \\
\hline CT4 & 39,43 & 29,05 \\
\hline$L S D_{0,5}$ & & 3,25 \\
\hline$C V \%$ & & 4,3 \\
\hline
\end{tabular}

Bảng 3: Ảnh hưởng lượng bón than sinh học đến năng suất của giống ngô VS36 


\subsection{Hiệu quả kinh tế của việc sủ̉ dụng than sinh học thay thế một phần phân khoáng bón cho cây ngô trên giống ngô VS36}

Qua bảng 4 cho thấy: Về lãi thuần và tỷ suất lợi nhuận cho thấy CT1 do phần thu được là cao nhất nên lãi thuần đạt được cũng cao nhất. CT2 mặc dù phần thu được ít hơn nhưng do tiết kiệm phân bón nên phần chi ít hơn nên lợi nhuận thu được thấp hơn không đáng kể và xét về tỷ suất lợi nhuận thì tương đương nhau. CT3, CT4 mặc dù phần chi có thấp hơn rất nhiều nhưng do lượng phân bón cho cây thấp nên năng suất đạt được thấp, phần thu thấp nên lãi thuần cũng thấp hơn nhiều so với đối chứng.

\begin{tabular}{|c|c|c|r|r|c|}
\hline $\begin{array}{l}\text { Công } \\
\text { thức }\end{array}$ & $\begin{array}{c}\text { NSTT } \\
(\mathbf{t a ̣} / \mathbf{h a})\end{array}$ & \multicolumn{1}{c|}{$\begin{array}{c}\text { Tổng thu } \\
\text { (d/ha) }\end{array}$} & \multicolumn{1}{c|}{$\begin{array}{c}\text { Tổng chi } \\
\text { (d/ha) }\end{array}$} & $\begin{array}{c}\text { Lãi thuần } \\
\text { (d/ha) }\end{array}$ & $\begin{array}{c}\text { Tỷ suất } \\
\text { lọi nhuận }\end{array}$ \\
\hline CT1 & 45,22 & 27.131 .327 & 13.045 .400 & 14.085 .928 & 1.08 \\
\hline CT2 & 42,68 & 25.605 .737 & 12.472 .400 & 13.133 .337 & 1.05 \\
\hline CT3 & 33,72 & 20.234 .089 & 11.046 .900 & 9.187 .189 & 0.83 \\
\hline CT4 & 29,05 & 17.432 .547 & 9.216 .400 & 8.216 .148 & 0.89 \\
\hline
\end{tabular}

Bảng 4: Hiệu quả kinh tế của việc bổ sung than sinh học bón cho cây ngô

\section{Kết luận}

+ Bón 10 tấn than sinh học thay thế cho $20 \%$ lượng phân khoáng bón cho 1ha ngô không ảnh hưởng đến sinh trưởng và năng suất của cây ngô.

+ Đối với giống ngô VS36, bón 10 tấn than sinh học thay thế cho 20\% lượng phân khoáng sẽ tiết kiệm được kinh phí đầu tư mà không làm suy giảm hiệu quả sản xuất.

\section{TÀI LIỆU THAM KHẢO}

1. Nguyễn Thế Hùng (1996), "Xác định chế độ bón phân tối ưu cho giống ngô LVN10 trên đất bạc màu vùng Đông Anh - Hà Nội”, Kết quả Nghiên cứu Khoa học Nông nghiệp 1995 - 1996, Nxb Nông nghiệp, Hà Nội.

2. Lehman, J., da Silva Jr., J. P., Steiner, C., Nehls, T., Zech, W. \& Glaser, B. (2003). Nutrient availability and leaching in an archaeological Anthrosol and a Ferralsol of the Central Amazon basin: fertilizer, manure and charcoal amendments. Plant Soil, 249, 343-357.

3. Lehmann J., Gaunt J. and Rondon M. (2006). "Biochar sequestration in terrestrial ecosystems - a review", Mitigation and Adaptation Strategies for Global Change, 11, 403 - 427.

4. Glaser B., Lehmann J., Zech W. (2002). Ameliorating physical and chemical properties of highly weathered soils in the tropics with charcoal - a review. Biology and Fertility of Soils 35: 219-230. 
5. Ishii, T. and K. Kadoya (1994). Effects of charcoal as a soilconditioner on citrus growth and vesicular-arbuscular mycorrhizal development. J. Japanese Soc. Hort. Sci., 63: 529-535.

6. Warnock, D.D., Lehmann J., Kuyper T.W. and Rillig M.C. (2007). Mycorrhizal responses to biochar in soil-concepts and mechanisms. Plant Soil, 300:9-20.

7. Van Zwieten L., S. KimberA, A. Downie, , S. MorrisA, S. Petty, , J. Rust, and K. Y. Chan. (2010). A glasshouse study on the interaction of low mineral ash biochar with nitrogen in a sandy soil. Australian Journal of Soil Research, 48:569-576.

8. Verheijen, F., Jeffery, S., Bastos, A.C., Velde, M.v.d., Diafas, I. (2009). Biochar Application to Soils - A Critical Scientific Review of Effects on Soil Properties, processes and functions. EUR 24099 EN. Office for the Official Publications of the European Communities, Luxemburg, p. 1-149. 